\title{
Comparative In Vitro Toxicity Study of Docetaxel and Nanoxel, a Docetaxel-Loaded Micellar Formulation Using Cultured and Blood Cells
}

\author{
Van Quan Do, Kwang-Hoon Park, Jung-Min Park and Moo-Yeol Lee \\ College of Pharmacy, Dongguk University, Goyang, Korea
}

\begin{abstract}
Nanoxel-PM ${ }^{\mathrm{TM}}$ (Nanoxel) is a docetaxel-loaded methoxy-poly(ethylene glycol)-block-poly(D,L-lactide) (mPEGPDLLA). This newly developed and marketed nanoformulation exhibits an improved pharmacokinetic profile, efficacy, and safety. Although the safety of Nanoxel to docetaxel as well as its bioequivalence must be clinically confirmed, all biological activities have not been examined in in vitro or in vivo studies. Here, the toxicity in a cultured cell system and the effects on blood cells were tested with Nanoxel and docetaxel. The in vitro cytotoxicity of Nanoxel was found to be comparable to or slightly lower than that of docetaxel depending on the concentrations tested or the cell types. Neither docetaxel nor Nanoxel induced erythrocytes hemolysis and produced reactive oxygen species up to $100 \mu \mathrm{M}$. However, Nanoxel was able to enhance the aggregatory response of platelets to collagen, whereas docetaxel attenuated such aggregation in a range of 50-100 $\mu \mathrm{M}$, while thrombin-induced aggregation was not affected by either of them. Docetaxel or Nanoxel did not alter basal level of $\mathrm{Ca}^{2+}$ and 5-hydroxytryptamine-evoked $\mathrm{Ca}^{2+}$ transient in vascular smooth muscle cells. These results suggest that the mPEG-PDLLA micellar formulation alters the toxicological properties of docetaxel, and that extra cautions are needed when evaluating the safety of nanomedicine.
\end{abstract}

Key words: Docetaxel, Nanoxel, Nanomedicine, Cytotoxicity, Platelet aggregation

\section{INTRODUCTION}

Docetaxel is a highly potent anticancer drug belonging to the taxane family (1). It exerts anti-proliferative activity through promoting the assembly of tubulin into stable microtubules and stabilizing the polymers against depolymerization, thereby blocking microtubule dynamics (2). Docetaxel has been used to treat a wide range of tumors, including advanced and metastatic cancer, non-small cell lung cancer, and advanced gastric cancer (3). As is the case with most chemotherapeutic agents, docetaxel also causes diverse adverse effects like neutropenia, leukopenia, neu-

Correspondence to: Moo-Yeol Lee, College of Pharmacy, Dongguk University, 32 Dongguk-ro, Ilsandong-gu, Goyang-si, Gyeonggi-do 10326, Korea

E-mail: mlee@dongguk.edu

This is an Open-Access article distributed under the terms of the Creative Commons Attribution Non-Commercial License (http:// creativecommons.org/licenses/by-nc/3.0) which permits unrestricted non-commercial use, distribution, and reproduction in any medium, provided the original work is properly cited. rological toxicity, alopecia, and asthenia in the majority of patients, which is a serious obstacle to its clinical use (4).

A good deal of effort has gone toward the development of novel delivery systems to improve therapeutic efficacy and reduce adverse reactions. To this end, nanotechnology has been applied to delivery systems, which, in general, enhances efficacy and potency by increasing surface area, solubility, and dissolution rate, and through the rapid onset of therapeutic action. Indeed, several drug delivery systems have been applied for docetaxel thus far, including docetaxel-loaded nanoparticles (5), self-emulsified docetaxel (6), malic acid-esterified docetaxel (7), and PEGylated liposomes (8) and N-palmitoyl chitosan-anchored liposome (9) for docetaxel.

Nanoxel-PM ${ }^{\mathrm{TM}}$ (Nanoxel) is a docetaxel-loaded methoxypoly(ethylene glycol)-block-poly(D,L-lactide) (mPEGPDLLA) micellar formulation (10). PDLLA was chosen as a hydrophobic core-forming material and mPEG segments were combined to form amphiphilic diblock copolymers. Mannitol was additionally used as a cryoprotectant. This formulation was employed so as to facilitate the solu- 
bilization of docetaxel, and thus does not require surfactants like Cremophor EL and polysorbate 80, which may cause hypersensitivity reactions and fluid retention. Accordingly, Nanoxel was reported to be superior to the conventional formulation of docetaxel in terms of efficacy, pharmacokinetic properties, and toxicity (10). Although its general safety has been shown and commercial marketing has been approved by the FDA, all the biological activities of Nanoxel were not compared with the active ingredient docetaxel.

In this study, the in vitro cytotoxicity of Nanoxel was tested in parallel with docetaxel. In addition, the effects on the circulatory system were examined as a primary target for injectable drugs. Primary cultured vascular smooth muscle cells (VSMCs) and the cell lines derived from vascular endothelium, circulating immune cell, and breast cancer were used for the cytotoxicity study. In order to test the effects on the circulatory system, platelet aggregation, the hemolysis of erythrocytes, and calcium signaling in VSMCs were examined. In addition, the reactive oxygen species (ROS)-generating capacity was assessed as a general toxicological property of nanomaterial.

\section{MATERIALS AND METHODS}

Reagents. Docetaxel and Nanoxel were purchased from Tokyo Chemical Industry (Tokyo, Japan) and Samyang Biopharmaceuticals (Seongnam, Korea), respectively. Thrombin, 5-hydroxytryptamine (5-HT), menadione, and butylated hydroxyanisole (BHA) were obtained from Sigma-Aldrich (St. Louis, MO, USA). Collagen was acquired from Chrono-log (Havertown, PA, USA) and 2-(4-iodophenyl)-3-(4-nitrophenyl)-5-(2,4-disulfophenyl)-2H-tetrazolium (WST-1) was obtained from Seoul Clinical Genomics (Seoul, Korea). Fura-2/AM and 10-acetyl-3,7-dihydroxyphenoxazine (Amplex Red) were purchased from Molecular Probes (Eugene, OR, USA). Premix WST-1 Cell Proliferation Assay System was acquired from Takara Bio (Shiga, Japan). All other chemicals used were of the highest purity available and purchased from standard suppliers.

Animals. All animal experiments were conducted in accordance with protocols approved by the Ethics Committee of Animal Service Center at Dongguk University. Male Sprague-Dawley rats were purchased at five to six weeks of age from Daehan Biolink (Eumseong, Korea). The rats were housed in the laboratory animal facility and acclimated for a week prior to experimentation. The laboratory animal facility was maintained at constant temperature and humidity with a $12 \mathrm{hr}$ light/dark cycle. Diet and water were provided ad libitum.

Cells and cell culture. VSMCs were isolated from rat thoracic aortas through enzymatic digestion as previously described (11). Briefly, isolated aortas were cut open longitudinally and cleaned of connective tissue, fat, and endothelium. Aortas were then digested with collagenase and elastase in order to remove the adventitia and dissociate the VSMCs. Individual cells were plated in a culture dish and grown in Dulbecco's modified Eagle's medium (DMEM) supplemented with $10 \%$ fetal bovine serum (FBS), $100 \mathrm{U} /$ $\mathrm{mL}$ penicillin, and $100 \mu \mathrm{g} / \mathrm{mL}$ streptomycin. Cells were passaged by trypsinization, and the passages between three and eight were used for experimentation.

The mouse brain endothelial cell line bEnd.3, human monocytic cell line THP-1, and human breast cancer cell line MCF-7 were purchased from American Type Culture Collection (Manassas, VA, USA). Cells were culture in DMEM (for bEnd.3 and MCF-7 cell lines) or Roswell Park Memorial Institute (RMPI) 1640 (for THP-1 cell line) supplemented with $10 \% \mathrm{FBS}, 100 \mathrm{U} / \mathrm{mL}$ penicillin, and $100 \mu \mathrm{g} / \mathrm{mL}$ streptomycin. Cells were maintained at $37^{\circ} \mathrm{C}$ and $5 \% \mathrm{CO}_{2}$ in a humidified chamber incubator and subcultured when they reached $80-90 \%$ confluence.

Measurement of cell lysis and viability. Cell lysis and viability were assessed by lactate dehydrogenase (LDH) leakage assay and formazan formation assay, as previously described (12). Briefly, cells were plated on multiwall plates at densities of $1 \times 10^{4}$ cells/well on a 96well plate and grown overnight until they reached $80-90 \%$ confluence. Cells were incubated with docetaxel or Nanoxel for $24 \mathrm{hr}$ before culture media were collected and centrifuged at $12,000 \mathrm{~g}$ for $2 \mathrm{~min}$. The resulting supernatant was used for LDH activity assay. Briefly, $50 \mu \mathrm{L}$ of the supernatant was added to $200 \mu \mathrm{L}$ of working reagent containing $0.2 \mathrm{mM} \mathrm{NADH}$ and $2.5 \mathrm{mM}$ sodium pyruvate in the individual wells of a 96-well plate. The decrease in absorbance at $340 \mathrm{~nm}$ was measured for 20 min with the SpectraMax M3 microplate reader (Molecular Devices, San Jose, CA, USA). Relative LDH activity was calculated from the slope of the graph of decreasing absorbance. LDH activities measured from 1\% Triton X-100treated cells were regarded as $100 \%$ lysis.

Following $24 \mathrm{hr}$ incubation with testing materials, the remaining cells were quantified in order to determine cell viability in the formazan formation assay. Treated cells were incubated with Premix WST-1 for an additional $2 \mathrm{hr}$. Media were then collected and centrifuged at 16,000 $\mathrm{g}$ for $2 \mathrm{~min}$. Cell viability was determined by measuring the absorbance at $450 \mathrm{~nm}$ with a reference wavelength of 630 $\mathrm{nm}$ using the SpectraMax M3 microplate reader.

Preparation of washed platelets (WP) and platelet aggregation studies. WP were prepared as previously described (13). Briefly, blood was collected from the abdominal aorta of rats anesthetized with ether using acid-citratedextrose (ACD; $85 \mathrm{mM}$ trisodium citrate, $66.6 \mathrm{mM}$ citric 
acid, and $111 \mathrm{mM}$ glucose) as an anticoagulant (ACD : blood $=1: 6$ ). After centrifugation at $400 \mathrm{~g}$ for $15 \mathrm{~min}$, platelet-rich plasma was obtained from the supernatant. Platelets were centrifuged again at $500 \mathrm{~g}$ for $10 \mathrm{~min}$, then washed once with washing buffer solution $(138 \mathrm{mM} \mathrm{NaCl}$, $2.8 \mathrm{mM} \mathrm{KCl}, 0.8 \mathrm{mM} \mathrm{MgCl}, 0.8 \mathrm{mM} \mathrm{Na} \mathrm{HPO}_{4}, 10 \mathrm{mM}$ HEPES, $0.55 \mathrm{mM}$ glucose, $22 \mathrm{mM}$ trisodium citrate, $0.35 \%$ bovine serum albumin; $\mathrm{pH}$ 6.5) by suspending and centrifuging. WP were prepared by resuspending the platelet pellets in suspension buffer solution $(138 \mathrm{mM} \mathrm{NaCl}, 2.8 \mathrm{mM}$ $\mathrm{KCl}, 0.8 \mathrm{mM} \mathrm{MgCl}_{2}, 0.8 \mathrm{mM} \mathrm{Na}_{2} \mathrm{HPO}_{4}, 10 \mathrm{mM}$ HEPES, 5.6 $\mathrm{mM}$ glucose, $1 \mathrm{mM} \mathrm{CaCl}{ }_{2}, 0.3 \%$ bovine serum albumin; $\mathrm{pH}$ 7.4). The number of cells was adjusted to $2 \times 10^{8}$ cells $/ \mathrm{mL}$.

Platelet aggregation experiments were performed using a four-channel aggregometer (Chrono-log). WP were treated with docetaxel or Nanoxel for $5 \mathrm{~min}$, and then aggregation was induced by either $2.5 \mu \mathrm{g} / \mathrm{mL}$ collagen or $0.12 \mathrm{U} /$ $\mathrm{mL}$ thrombin, which is the concentration inducing approximately $50 \%$ aggregation.

Preparation of erythrocyte suspension and measurement of hemolysis. Erythrocyte suspension was prepared and hemolysis was assessed as previously described (14). Briefly, blood was withdrawn from the abdominal aorta of ether-anesthetized rats and subjected to centrifugation at $1,000 \mathrm{~g}$ for $10 \mathrm{~min}$. The buffy coat was then removed, and remaining erythrocytes were washed twice with phosphate-buffered saline (PBS; $6 \mathrm{mM}$ sodium phosphate, $140 \mathrm{mM} \mathrm{NaCl}$; pH 7.4). Erythrocytes were suspended in PBS to a final count of $2 \times 10^{9} \mathrm{cell} / \mathrm{mL}$.

Erythrocytes were incubated with docetaxel or Nanoxel at $37^{\circ} \mathrm{C}$ with $300 \mathrm{rpm}$ stirring using ThermoMixer (Eppendorf, Hamburg, Germany). An aliquot of suspension was taken out at indicated time points and centrifuged at $10,000 \mathrm{~g}$ for $1 \mathrm{~min}$ in order to obtain suspension media. Hemolysis was assessed by measuring a light absorbance at $540 \mathrm{~nm}$ using the SpectraMax M3 microplate reader. Percent hemolysis was expressed as the ratio of the light absorbance of test sample compared to a standard sample completely hemolyzed with $1 \%$ Triton X-100.

ROS measurement in VSMCs. ROS were quantified with the colorimetric probe WST-1 and the fluorescent probes Amplex Red. VSMCs were treated with docetaxel or Nanoxel in the presence of $500 \mu \mathrm{M}$ WST-1 or $10 \mu \mathrm{M}$ Amplex Red and 0.1 U/mL HRP for WST-1 or Amplex Red assays, respectively. The absorbance at $450 \mathrm{~nm}$ or fluorescence intensity at $\mathrm{Ex} / \mathrm{Em}=560 / 585 \mathrm{~nm}$ was measured at 12- or 3-min intervals for 60 or $12 \mathrm{~min}$, respectively, using the SpectraMax M3 microplate reader. All assays were performed at $37^{\circ} \mathrm{C}$.

$\mathrm{Ca}^{2+}$ measurement in VSMCs. Intracellular $\mathrm{Ca}^{2+}$ was measured using the fluorometric method employing a fura-
2 and digital imaging, as previously described (15). Briefly, VSMCs grown on coverslips were incubated in physiological salt solution (PSS; $140 \mathrm{mM} \mathrm{NaCl}, 5 \mathrm{mM} \mathrm{KCl}, 5 \mathrm{mM}$ $\mathrm{NaHCO}_{3}, 1.8 \mathrm{mM} \mathrm{CaCl}_{2}, 1.4 \mathrm{mM} \mathrm{MgCl}_{2}, 1.2 \mathrm{mM} \mathrm{NaH}_{2} \mathrm{PO}_{4}$, $11.5 \mathrm{mM}$ glucose, and $10 \mathrm{mM}$ HEPES; $\mathrm{pH}$ 7.4) containing $1 \mu \mathrm{M}$ fura-2/AM, $1 \%$ bovine serum albumin and $1 \mu \mathrm{M}$ docetaxel or Nanoxel for $60 \mathrm{~min}$. Coverslips were mounted in a superfusion chamber on the microscope stage and continuously superfused with PSS at a rate of $2 \mathrm{~mL} / \mathrm{min}$. $\mathrm{Ca}^{2+}$ transient was evoked with $10 \mu \mathrm{M}$ 5-HT. All experiments were conducted at $33^{\circ} \mathrm{C}$. Cells were imaged with a Nikon Eclipse Ti-U inverted microscope equipped with a S Fluor 40× objective lens (Nikon, Tokyo, Japan) and an Evolve 512 electron-multiplying charge-coupled device camera (Photometrics, Tucson, AZ, USA). Illumination was provided by a Sutter DG-4 filter changer (Sutter Instruments, Novato, CA, USA). The excitation and emission wavelengths used for fura-2 were $340 / 380$ and $535 \mathrm{~nm}$, respectively. Images were acquired and analyzed using a Meta Imaging System (Molecular Devices).

Statistical analyses. Means and standard errors (SE) of means were calculated for all experimental groups. Data were subjected to one-way or two-way analysis of variance followed by Dunn's test in order to determine the significances of the differences relative to controls. Statistical analysis was performed using SigmaPlot software version 13.0 (Systat Software, San Jose, CA, USA). $P$ values of $<0.05$ were considered to be statistically significant.

\section{RESULT}

Cytotoxicity of docetaxel and Nanoxel. The cytotoxic potentials of docetaxel and Nanoxel were evaluated in VSMCs, bEnd.3 cells, THP-1 cells, and MCF-7 cells. Cell lysis and viability were measured by LDH leakage assay and WST-1 assay, respectively. Both docetaxel and Nanoxel exhibited moderate but statistically significant cytotoxicity, and such cytotoxicity was concentrationdependent in a range of $1 \mathrm{nM}-100 \mu \mathrm{M}$ (Fig. 1). The extent of cytotoxicity differed depending on cell types; VSMCs and bEnd. 3 were more vulnerable to docetaxel and Nanoxel than were THP-1 and MCF-7. The cytotoxicity of Nanoxel was comparable to or less cytotoxic than that of docetaxel, depending on cell types. The difference of cytotoxicity between them was prominent in the relatively high concentrations of 10 and $100 \mu \mathrm{M}$ (Fig. 1).

Hemolytic activity of docetaxel and Nanoxel. Docetaxel and Nanoxel were tested for their hemolytic activities using erythrocyte suspension prepared from rat whole blood. The erythrocyte suspension was treated with 10-100 $\mu \mathrm{M}$ docetaxel or Nanoxel and incubated for 30-180 min. Docetaxel or Nanoxel failed to cause hemolysis up to 180 


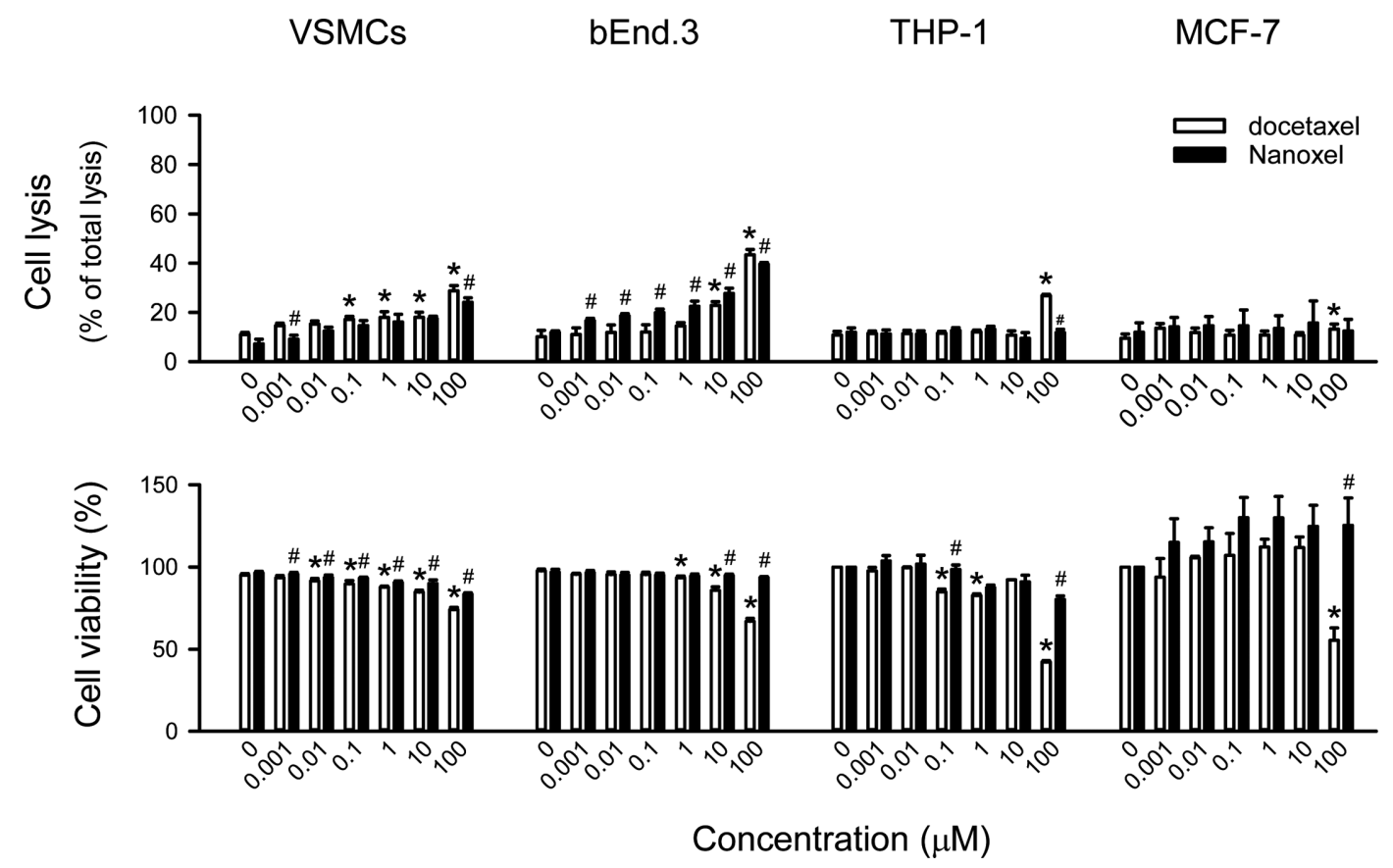

Fig. 1. Effects of docetaxel and Nanoxel on the survival of cells. Cells were treated with the indicated concentrations of docetaxel or Nanoxel. After $24 \mathrm{hr}$, cell lysis and viability were measured by LDH leakage assay and formazan formation assay, respectively. All values are mean \pm standard error $(\mathrm{n}=3)$. ${ }^{*} p<0.05$ vs. control, ${ }^{*} p<0.05$ vs. docetaxel.
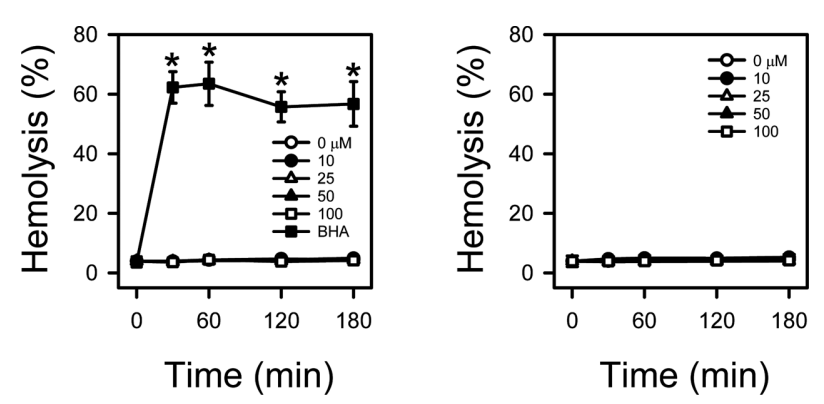

Fig. 2. Assessment of hemolysis of erythrocytes exposed to docetaxel (left panel) and Nanoxel (right panel). Erythrocyte suspension was treated with docetaxel or Nanoxel, and hemolysis was assessed after 30,60, 120, and $180 \mathrm{~min}$ incubation. As a positive control, erythrocytes were treated with $10 \mathrm{mM}$ BHA. All values are mean \pm standard error $(n=3)$.

min (Fig. 2). For a positive control, erythrocytes were treated with $10 \mathrm{mM}$ BHA, which successfully induced hemolysis under this experimental condition (Fig. 2, left panel).

\section{Effect of docetaxel and Nanoxel on platelet aggrega-}

tion. Docetaxel or Nanoxel treatment alone did not induce platelet aggregation (data not shown). In order to test the effect on platelet aggregation, WP were preincubated with docetaxel or Nanoxel for $5 \mathrm{~min}$ and aggregation was induced by the application of collagen or thrombin. Docetaxel could inhibit platelet aggregation induced by collagen at higher than $50 \mu \mathrm{M}$, and it was not effective at lower concentrations (Fig. 3A). In contrast, Nanoxel enhanced platelet aggregation at 50 and $75 \mu \mathrm{M}$, while the higher concentration of $100 \mu \mathrm{M}$ did not affect aggregation. Platelet aggregation by thrombin was not significantly affected by pretreatment of docetaxel or Nanoxel (Fig. 3B).

\section{ROS generating capability of docetaxel and Nanoxel} in VSMCs. ROS generation by docetaxel and Nanoxel was measured using WST-1 and Amplex Red in VSMCs. WST-1 is a specific probe for superoxide anion and Amplex Red selectively detects hydrogen peroxide (16). Neither docetaxel nor Nanoxel were capable of generating superoxide or hydrogen peroxide in a range of 0.1$100 \mu \mathrm{M}$ (Fig. 4). Menadione was used as a positive control and it successfully produced superoxide and hydrogen peroxide at $50 \mu \mathrm{M}$.

Effects of docetaxel and Nanoxel on the $\mathrm{Ca}^{2+}$ signaling in VSMCs. Intracellular $\mathrm{Ca}^{2+}$ in vascular smooth muscle is a major determinant of vasomotor function, and thus the impact of docetaxel and Nanoxel on $\mathrm{Ca}^{2+}$ signaling was tested in VSMCs. Neither docetaxel alone nor Nanoxel alone were found to affect the basal level of intracellular $\mathrm{Ca}^{2+}$ (Fig. 5B). Then, the impact on intracellular $\mathrm{Ca}^{2+}$ elevation was examined with a vasoconstrictor 5-HT. When cells were stimulated with $10 \mu \mathrm{M} 5-\mathrm{HT}$, typical $\mathrm{Ca}^{2+}$ tran- 
(A)

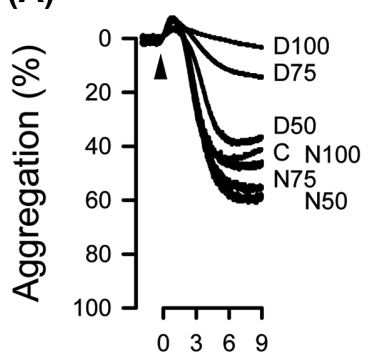

Time (min)

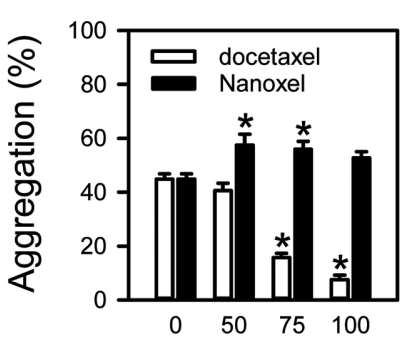

Concentration $(\mu \mathrm{M})$
(B)

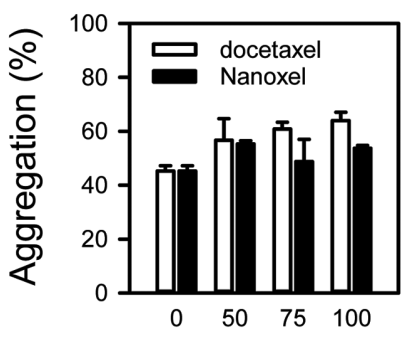

Concentration $(\mu \mathrm{M})$

Fig. 3. Effects of docetaxel and Nanoxel on platelet aggregation. WP were pretreated with the indicated concentrations of docetaxel (D) or Nanoxel (N) for $5 \mathrm{~min}$. Aggregation was induced by the addition of (A) $2.5 \mu \mathrm{g} / \mathrm{mL}$ collagen or (B) $0.12 \mathrm{U} / \mathrm{mL}$ thrombin. Representative tracings (left panel of $A$ ) and the aggregation percentages relative to the control (right panel of $A$ and $B$ ) are presented. Arrowhead in panel A indicates collagen application. All values are mean \pm standard error $(n=3) .{ }^{*} p<0.05$ vs. control.

(A)
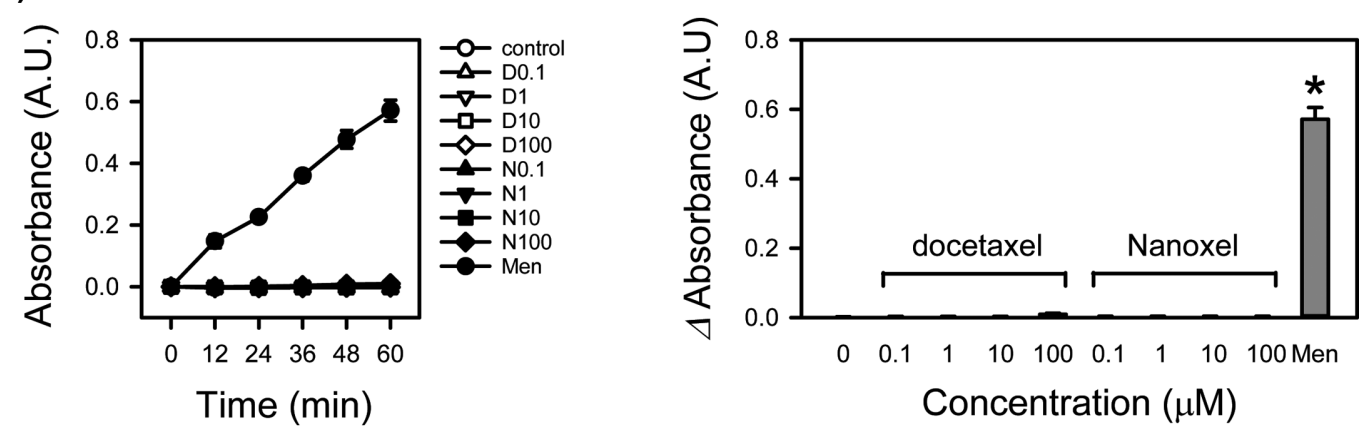

(B)
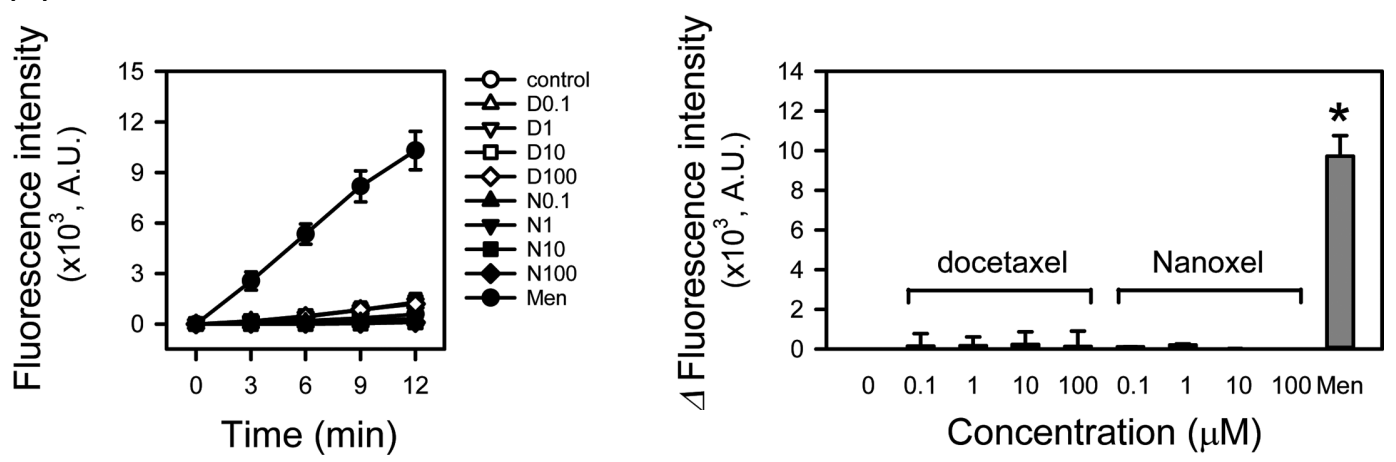

Fig. 4. Assessment of ROS production in VSMCs treated with docetaxel or Nanoxel. Cells were treated with docetaxel or Nanoxel, and superoxide and hydrogen peroxide were measured with (A) WST-1 and (B) Amplex Red, respectively. The time courses of ROS production and the total production of ROS were presented in the left and right panels, respectively. For a positive control, cells were treated with $50 \mu \mathrm{M}$ menadione (Men). All values are mean \pm standard error $(n=3)$.

sient was evoked (Fig. 5A, upper panels). However, such $\mathrm{Ca}^{2+}$ transient was not altered by pretreatment with $1 \mu \mathrm{M}$ docetaxel or Nanoxel for $60 \mathrm{~min}$ (Fig. 5A, lower panel). There was no statistical difference in the amplitude of $\mathrm{Ca}^{2+}$ peak (Fig. 5B).

\section{DISCUSSION}

Several novel formulations of docetaxel have been intro- duced in the market and widely prescribed to patients (17). Nanoxel is one of the recently developed nanoformulations of docetaxel. Although the bioequivalence of Nanoxel to docetaxel and its safety must be clinically confirmed, all biological activities have not been examined in in vitro or in vivo studies. Here, the toxicity in a cultured cell system and the effects on blood cells such as erythrocytes and platelets were tested with Nanoxel and docetaxel in parallel. The in vitro cytotoxicity of Nanoxel was found to be 
(A)

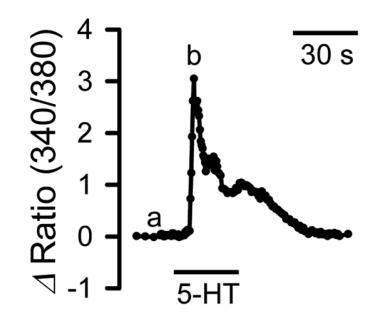

docetaxel

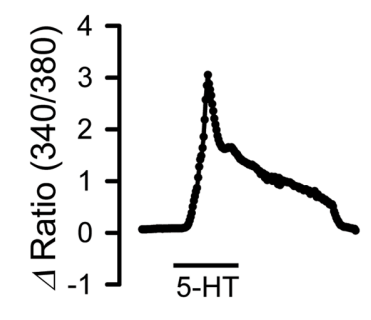

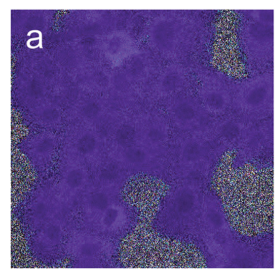

Nanoxel

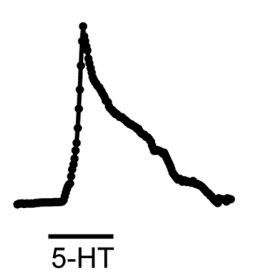

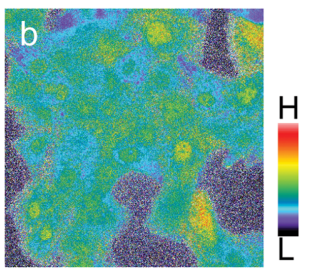

(B)
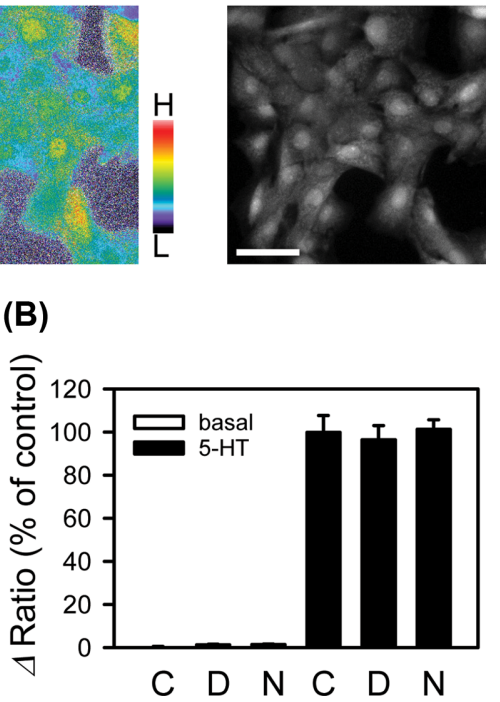

Fig. 5. Effects of docetaxel and Nanoxel on the $\mathrm{Ca}^{2+}$ signals in VSMCs. Fura-2-loaded VSMCs were incubated with docetaxel or Nanoxel for $60 \mathrm{~min}$ and $\mathrm{Ca}^{2+}$ transient was evoked by the application of $10 \mu \mathrm{M} \mathrm{5-HT}$. (A) Representative tracings for $\mathrm{Ca}^{2+}$ level detected by fura-2. Cell image captured at $380 \mathrm{~nm}$ wavelength was shown in the right of upper panel, and pseudocolor images of fura- 2 captured at time points ' $a$ ' and ' $b$ ' were presented in the middle of the upper panels. The bars at the bottom of each tracing correspond to periods when $5-\mathrm{HT}$ was applied. The relative color scale in the upper panel indicates low $(\mathrm{L})$ and high $(\mathrm{H}) \mathrm{Ca}^{2+}$ concentrations. Scale bar $=50 \mu \mathrm{M}$. (B) Basal (white bar) or $10 \mu \mathrm{M}$ 5-HT-evoked (black bar) $\mathrm{Ca}^{2+}$ levels in control (C) and cells treated with docetaxel $(D)$ or Nanoxel $(N)$. All values are mean \pm standard error $(n=25)$.

comparable or slightly lower than that of docetaxel, depending on the concentration tested or the cell types (Fig. 1). Nanoxel or docetaxel did not exhibit hemolytic activity in erythrocytes (Fig. 2), failed to produce ROS in cultured cells (Fig. 4), and did not affect intracellular $\mathrm{Ca}^{2+}$ signals (Fig. 5). However, their effects on platelets differed from each other; Nanoxel was able to enhance the aggregatory response of platelets to collagen, whereas docetaxel attenuated such aggregation. The mechanism underlying distinct platelet effects was not clarified in this study. However, this observation raises the possibility that the mPEGPDLLA micellar formulation alters the toxicological properties of docetaxel. Accordingly, extra cautions will be needed to evaluate the safety of nanomedicine.

Both docetaxel and Nanoxel are generally administered by $i . v$. route, and thus their primary exposure targets are blood and the vascular system. Hence, the toxicity or safety in these tissues must be tested, and the impacts on blood and vascular cells were examined in this study. Neither docetaxel nor Nanoxel caused hemolysis of erythrocytes up to $100 \mu \mathrm{M}$ of concentration and $3 \mathrm{hr}$ of treatment time (Fig. 2). The in vitro hemolytic activity of docetaxel has been previously reported $(18,19)$, but this is not in agreement with the results of this study. The reason for the discrepancy is unknown, but the testing material itself may be responsible for such a difference. For instance, previous studies used Tween 80 and ethanol as vehicles for docetaxel, which are from marketed docetaxel $(18,19)$, while $0.1 \%$ dimethyl sulfoxide was used as a vehicle in this study. Although Tween 80 and ethanol are generally regarded to be biocompatible, the combination of Tween 80 and ethanol is well known for its nonspecific toxicity and may enhance the toxicity of docetaxel (20,21). Further study is needed regarding the hemolytic properties of docetaxel and Nanoxel.

Striking differences between docetaxel and Nanoxel were found in the platelet study (Fig. 3); docetaxel was able to inhibit platelet aggregation. Although the anti-aggregatory activity of docetaxel has never been studied, it may well suppress aggregation considering its mode of action, stabilizing microtubule structure, because cytoskeletal dynamics are also critical events in the process of platelet aggregation. However, such an anti-aggregatory effect was seen only in collagen-induced aggregation, not in aggregation by thrombin. If the impact on cytoskeleton is the only mechanism contributing to aggregation inhibitory activity, docetaxel would be effective against not only collagen but also thrombin. Therefore, mechanisms other than microtubule-stabilizing activity must be involved in the anti-aggregatory activity of docetaxel, but these remain elusive. In contrast to docetaxel, Nanoxel enhanced platelet aggregation by collagen without any effect on thrombin-induced aggregation. This difference must be ascribed to the difference in docetaxel formulation. Thus, it is 
likely that the micellar formulation employed in the preparation of Nanoxel has a pro-aggregatory effect. The molecular mechanism underlying the platelet effect of Nanoxel formulation must be investigated further. This observation suggests the necessity for more detailed safety evaluation of nanoformulations.

ROS generating capability is one of the characteristics of nanomaterials due to the larger surface area and the increased probability of chemical reactions on surface (22). However, such a characteristic appears to be limited to inorganic nanoparticles. Liposomes or micelles with organic surfaces composed of lipids and polymers did not produce ROS. This was also the case with the mPEG-PDLLA micellar formulation of Nanoxel (Fig. 4). Presumably, ROS production is not the main concern of nanoformulations in terms of toxicity.

\section{ACKNOWLEDGMENTS}

This research was supported by a grant (16173MFDS542) from Ministry of Food and Drug Safety in 2018.

\section{CONFLICT OF INTEREST}

The authors have no conflict of interest to disclose.

Received August 29, 2018; Revised September 18, 2018; Accepted October 4, 2018

\section{REFERENCES}

1. Takimoto, C.H. and Beeram, M. (2008) Microtubule stabilizing agents in clinical oncology in The Role of Microtubules in Cell Biology, Neurobiology, and Oncology (Fojo, T. Ed.). Humana Press, Totowa, NJ, pp. 395-419.

2. Herbst, R.S. and Khuri, F.R. (2003) Mode of action of docetaxel - a basis for combination with novel anticancer agents. Cancer Treat. Rev., 29, 407-415.

3. Clarke, S.J. and Rivory, L.P. (1999) Clinical pharmacokinetics of docetaxel. Clin. Pharmacokinet., 36, 99-114.

4. Kenmotsu, H. and Tanigawara, Y. (2015) Pharmacokinetics, dynamics and toxicity of docetaxel: why the Japanese dose differs from the Western dose. Cancer Sci., 106, 497-504.

5. Yanasarn, N., Sloat, B.R. and Cui, Z. (2009) Nanoparticles engineered from lecithin-in-water emulsions as a potential delivery system for docetaxel. Int. J. Pharm., 379, 174-180.

6. Kim, G.H., Lee, J.Y., Kang, Y.M., Kang, K.N., Kim, E.S., Kim, D.Y., Kim, J.H. and Kim, M.S. (2011) Preparation and characterization of self-emulsified docetaxel. J. Nanomater, 2011, 6.

7. Du, W., Hong, L., Yao, T., Yang, X., He, Q., Yang, B. and $\mathrm{Hu}$, Y. (2007) Synthesis and evaluation of water-soluble docetaxel prodrugs-docetaxel esters of malic acid. Bioorg. Med. Chem., 15, 6323-6330.

8. Naik, S., Patel, D., Surti, N. and Misra, A. (2010) Preparation of PEGylated liposomes of docetaxel using supercritical fluid technology. J. Supercrit. Fluids, 54, 110-119.
9. Liang, G., Jia-Bi, Z., Fei, X. and Bin, N. (2010) Preparation, characterization and pharmacokinetics of N-palmitoyl chitosan anchored docetaxel liposomes. J. Pharm. Pharmacol., 59, 661-667.

10. Lee, S.-W., Yun, M.-H., Jeong, S.W., In, C.-H., Kim, J.-Y., Seo, M.-H., Pai, C.-M. and Kim, S.-O. (2011) Development of docetaxel-loaded intravenous formulation, Nanoxel-PM ${ }^{\mathrm{TM}}$ using polymer-based delivery system. J. Control. Release, 155, 262-271.

11. Lee, M.Y., Song, H., Nakai, J., Ohkura, M., Kotlikoff, M.I., Kinsey, S.P., Golovina, V.A. and Blaustein, M.P. (2006) Local subplasma membrane $\mathrm{Ca}^{2+}$ signals detected by a tethered $\mathrm{Ca}^{2+}$ sensor. Proc. Natl. Acad. Sci. U.S.A., 103, 13232-13237.

12. Oh, S.-J., Kim, H., Liu, Y., Han, H.-K., Kwon, K., Chang, K.-H., Park, K., Kim, Y., Shim, K., An, S.S.A. and Lee, M.-Y. (2014) Incompatibility of silver nanoparticles with lactate dehydrogenase leakage assay for cellular viability test is attributed to protein binding and reactive oxygen species generation. Toxicol. Lett., 225, 422-432.

13. Liu, Y., Park, J.-M., Chang, K.-H., Huh, H.J., Lee, K. and Lee, M.-Y. (2016) AMP-activated protein kinase mediates the antiplatelet effects of the thiazolidinediones rosiglitazone and pioglitazone. Mol. Pharmacol., 89, 313-321.

14. Park, J.-M., Chang, K.-H., Park, K.-H., Choi, S.-J., Lee, K., Lee, J.-Y., Satoh, M., Song, S.-Y. and Lee, M.-Y. (2016) Differential effects between cigarette total particulate matter and cigarette smoke extract on blood and blood vessel. Toxicol. Res., 32, 353-358.

15. Park, J.-M., Lee, J.-H., Na, C.-S., Lee, D., Lee, J.-Y., Satoh, M. and Lee, M.-Y. (2016) Heartwood extract of Rhus verniciflua Stokes and its active constituent fisetin attenuate vasoconstriction through calcium-dependent mechanism in rat aorta. Biosci. Biotechnol. Biochem., 80, 493-500.

16. Chang, K.H., Park, J.M., Lee, C.H., Kim, B., Choi, K.C., Choi, S.J., Lee, K. and Lee, M.Y. (2017) NADPH oxidase (NOX) 1 mediates cigarette smoke-induced superoxide generation in rat vascular smooth muscle cells. Toxicol. In Vitro, 38, 49-58.

17. Ojima, I., Lichtenthal, B., Lee, S., Wang, C. and Wang, X. (2016) Taxane anticancer agents: a patent perspective. Expert Opin. Ther. Pat., 26, 1-20.

18. Huang, X.-X., Zhou, C.-L., Wang, H., Chen, C., Yu, S.-Q., Xu, Q., Zhu, Y.-Y. and Ren, Y. (2011) Pharmacokinetics, efficacy, and safety evaluation of docetaxel/hydroxypropylsulfobutyl- $\beta$-cyclodextrin inclusion complex. AAPS PharmSciTech, 12, 665-672.

19. Wang, Y.B., Wang, J.C., Meng, M., Zhang, H. and Zhang, Q. (2010) Preparation and evaluation of docetaxel-loaded albumin nanoparticles for intravenous administration. J. Chin. Pharm. Sci., 19, 214-222.

20. Engels, F.K., Mathot, R.A.A. and Verweij, J. (2007) Alternative drug formulations of docetaxel: a review. Anticancer Drugs, 18, 95-103.

21. Elm'hadi, C., Tanz, R., Khmamouche, M.R., Toreis, M., Mahfoud, T., Slimani, K.A., Errihani, H. and Ichou, M. (2016) Toxicities of docetaxel: original drug versus genericsa comparative study about 81 cases. SpringerPlus, 5, 732.

22. Fu, P.P., Xia, Q., Hwang, H.-M., Ray, P.C. and Yu, H. (2014) Mechanisms of nanotoxicity: generation of reactive oxygen species. J. Food Drug Anal., 22, 64-75. 